\title{
Restauração Audiovisual: apontamentos conceituais, históricos e sua apropriação no Brasil
}

\author{
Débora Butruce
}

\begin{abstract}
Resumo
A restauração audiovisual é tema que vem ganhando destaque nas pesquisas sobre o campo da preservação audiovisual que proliferaram, sobretudo, a partir dos anos 2000. Neste artigo, apresentamos os principais conceitos sobre a área, buscando trazer à tona a questão do original na obra audiovisual, além de procurarmos localizar o contexto histórico que possibilitou o início do aprofundamento da discussão em torno das práticas de restauro. $\mathrm{Na}$ tentativa de exemplificar como o conceito de original foi incorporado pela área de restauração audiovisual no Brasil, utilizaremos o caso do filme Bonequinha de seda (Oduvaldo Viana, 1936).
\end{abstract}

\section{Palavras-chave:}

Audiovisual; Preservação; Restauração; Cinema brasileiro; Materiais cinematográficos.

\begin{abstract}
The audiovisual restoration is a topic that has been gaining prominence in the researches on the field of audiovisual preservation that proliferated, mainly, from the years 2000. In this article, we present the main concepts about the area, seeking to bring up the question of the original in the audiovisual work, besides trying to locate the historical context that enabled the beginning of the deepening of the discussion around the restoration practices. In an attempt to exemplify how the original concept was incorporated by the area of audiovisual restoration in Brazil, we will use the case of the film Bonequinha de seda (Oduvaldo Viana, 1936).
\end{abstract}

\section{Keywords:}

Audiovisual; Preservation; Restoration, Brazilian cinema; Cinematographic materials.

O campo da preservação audiovisual no Brasil vem passando, nos últimos anos, por um processo de amadurecimento e transformação ${ }^{2}$ que pode ser observado, entre outros fatores, pelo significativo aumento dos estudos sobre a área ${ }^{3}$.Antes de mais nada, é necessário esclarecermos o que se entende por preservação audiovisual.

Preservação audiovisual é o conjunto dos procedimentos, técnicas e práticas necessários para a manutenção da integridade do documento audiovisual, em seus variados suportes, e a garantia permanente da possibilidade de sua experiência intelectual.A preservação engloba uma série de atividades, dentre elas a prospecção e a coleta, a catalogação, a conservação, a duplicação, a migração,

I Doutoranda em Meios e Processos Audiovisuais na Escola de Comunicações e Artes da USP.

2 Podemos incluir a criação da disciplina Preservação, Restauração e Política de Acervos Audiovisuais, no curso de Cinema da Universidade Federal Fluminense (UFF), em 2000, como um dos momentos que auxiliaram no processo de consolidação da área de preservação audiovisual no Brasil. Fui aluna da primeira turma.

3 Uma listagem abrangente pode ser encontrada na dissertação de mestrado de Silvia Ramos Gomes da Costa (2013, pp. I20-121). Além destes trabalhos, podemos citar as dissertações de Alexandre Vasques (20I2) e de Joice Scavone Costa (20I3). 
a restauração, a reconstrução (quando necessário), a recriação das condições de apresentação, a documentação, a difusão e o acesso, além da pesquisa e a reunião de informações para realizar adequadamente todas essas atividades ${ }^{4}$. A restauração ${ }^{5}$ é um importante aspecto do conjunto de práticas que constituem a atividade de preservação, e vem ganhando destaque nas pesquisas sobre a área.A bibliografia estrangeira dedicada ao assunto também vem aumentando, $\mathrm{e}$ tentativas no sentido de definir teoricamente o campo da restauração audiovisual vêm sendo realizadas, em especial por pesquisadores europeus.

Uma das questões principais é o controverso conceito do que seria o original em uma obra audiovisual. $O$ manuseio de uma obra em película fotoquímica acarreta danos inevitáveis e progressivos, o que gera a necessidade de duplicação do seu conteúdo para um novo suporte. Já no universo digital, é a obsolescência tecnológica dos formatos e de seus equipamentos de reprodução que demandam a periódica migração dos conteúdos. Portanto, quando se aplica o termo restauração aos artefatos ${ }^{6}$ audiovisuais, deve-se levar em conta sua especificidade em relação à maior parte das outras artes, visto que ela necessariamente envolve a reprodução de um material original. Mas o que seria este material original? Retomaremos essa questão, de forma mais detida, adiante.

\section{O conceito de restauração audiovisual}

Para Paolo Cherchi Usai, em Silent cinema: an introduction (2000), a restauração audiovisual é "o conjunto de procedimentos técnicos, editoriais e intelectuais destinados a compensar a perda ou degradação do artefato imagem em movimento, e, desta forma, trazê-lo de volta ao estado mais próximo possível de sua condição original"'. (CHERCHI USAI, 2000: 66) ${ }^{8}$.

Nesse sentido, a restauração já acarretaria alterações no estado em que se encontra o objeto visando o restabelecimento de seu estado original. $O$ autor considera que a remoção de alterações ou manipulações detectadas no artefato durante o processo de reprodução e a inclusão de elementos faltantes (a partir de práticas de reconstrução), com a finalidade de reverter os efeitos da manipulação (inapropriada ou não) ao longo do tempo e o desgaste óptico e cromático dos suportes de imagens em movimento são etapas integrantes do trabalho de restauração. Tomadas individualmente, nenhuma delas é suficiente para cumprir os requisitos de uma restauração audiovisual.

Já Paul Read e Mark-Paul Meyer, em Restoration of motion picture film (2000), livro voltado, sobretudo, para os aspectos técnicos e práticos da restauração audiovisual, afirmam que a restauração consiste, essencialmente, de duplicação, sendo que esta seria a única maneira de preservar as imagens em movimento. Entretanto, as técnicas de duplicação no universo fotoquímico possuem limitações inerentes e, desta forma, cada processo representa uma alteração em

4 Esta definição é uma tradução/adaptação de algumas definições existentes em Ray Edmondson (20I3), Paolo Cherchi Usai (2000) e Carlos Roberto de Souza (2009).

5 Apesar deste artigo estar circunscrito ao universo da restauração de filmes no suporte fotoquímico, ou seja, realizados em película cinematográfica, acreditamos que o termo audiovisual é mais abrangente e, portanto, mais adequado atualmente, pois inclui campos distintos da produção e realização de imagens em movimento.

6 Artefato: forma individual de cultura material ou produto deliberado da mão de obra humana (Dicionário Houaiss).

7 No original:"Restoration is the set of technical, editorial and intellectual procedures aimed at compensating for the loss or degradation of the moving image artifact, thus bringing it back to a state as close as possible to its original condition."

8 Todas as traduções dos textos originalmente em inglês foram feitas pela autora. 
relação aos materiais de origem.

Os autores deixam, ainda mais clara, a característica interventora da restauração, explicitando que a natureza do próprio processo de reprodução já acarreta inevitáveis alterações e que, por conta disso, determinados princípios devem ser sempre observados, tanto em uma duplicação simples, com o mínimo de intervenções, até as mais complexas, com o máximo de manipulações. Deve-se ter atenção, principalmente, no momento de transferência de um material em película para outro suporte, como o digital, por exemplo.

Por conseguinte, o retorno do material à sua condição original, mesmo que de forma parcial, não seria possível. Ainda que as definições de Read e Meyer se restrinjam aos procedimentos fotoquímicos da restauração audiovisual, o conceito pode ser estendido ao universo digital, pois mesmo que a reprodução de uma obra fílmica para um formato digital não implique em perda de qualidade, a natureza da formação da imagem (e da gravação dos sons) no digital é diferente do padrão analógico e, portanto, a reformatação dos materiais é imprescindível. Ou seja, alterações são, sempre, inevitáveis.

A definição de Julia Wallmüller, expressa em seu artigo Criteria for the use of digital technology in moving image restoration (2007), também reforça o caráter interventor da restauração audiovisual, explicitando e diferenciando conceitos importantes para o campo, como os de dano, erro e defeito.

Dano seria os vestígios das manipulações ocorridas ao longo do tempo, a deterioração físico-química, além do uso ou mau uso do material, como riscos, rasgos, impressões digitais, manchas, encolhimento e esmaecimento da cor, entre outros. Erro se refere às modificações na obra que não pertençam ao seu conteúdo original, advindas do tratamento a que o trabalho foi submetido. Uma duplicação malfeita que não respeitou a proporção de tela original, ocasiona, por exemplo, subtração de parte da imagem nas laterais dos fotogramas. $O$ defeito, por fim, pode ser um dano ou um erro que ocasiona um efeito visual (e/ou acústico) no artefato audiovisual, que pode ser oriundo da produção da época e que passa, portanto, a fazer parte de suas características originais, devendo ser encarados como integrantes do trabalho original ${ }^{9}$.

A autora considera que a restauração pode ser compreendida como uma intervenção na parte física ou visual de um filme, cuja finalidade é reduzir ou remover danos e erros ao mesmo tempo em que preserva defeitos inerentes ao trabalho no momento da produção.

Sua definição evidencia as diferentes possibilidades de intervenção em uma obra audiovisual e destaca a importância de se respeitar todas as características originais do material, mesmo em relação ao que possa ser considerado defeito de produção. Este aspecto é bastante relevante, pois chama atenção para os limites do trabalho de restauração audiovisual, antecipando questões acerca das complexas decisões que um profissional da área pode vir a ser obrigado a tomar.

Como podemos observar, a partir dos exemplos acima mencionados, a maioria das definições sobre restauração audiovisual inclui a ideia de retorno à condição original do filme. A ideia subjacente é que existiria um estado de origem ao qual seria possível retornar (ou ao menos se aproximar) através da

9 A autora participou do projeto de restauração digital da obra do cineasta Joaquim Pedro de Andrade, no qual debateu-se intensamente acerca da possibilidade de apagar (por meio dos softwares de restauro utilizados) um tubo de plástico por onde o sangue cenográfico na cena final de Macunaíma (1969) é expelido. Mesmo sendo parte de um efeito especial que deveria, a princípio, ser imperceptível, o defeito foi considerado parte integrante da condição original do filme e, portanto, foi mantido. 
restauração. No entanto, o conceito de original é bastante controverso no universo audiovisual. Segundo Cherchi Usai (2000, p. I60), “a versão 'original' de um filme é um objeto múltiplo, fragmentado em um número de diferentes entidades equivalente ao número de materiais sobreviventes"10 . $\mathrm{O}$ autor considera que os artefatos fílmicos (negativo de imagem, negativo de som, máster, internegativo, cópia etc.) são objetos que possuem uma evidência histórica, uma vez que cada um deles teria características particulares que podem ser determinantes nos resultados de um trabalho de restauração" ". Logo, cada artefato fílmico é merecedor de um tratamento peculiar, pois tanto os negativos ou uma cópia de difusão podem ser considerados as matrizes de uma restauração, já que detêm características originais intrínsecas à sua própria materialidade.

Este valor de evidência histórica dos artefatos fílmicos, portanto, deve ser reconhecido por parte dos profissionais de arquivos de filmes e restauradores, uma vez que apresentam características semelhantes às das obras de arte tradicionais, no sentido de que cada um deles possui qualidades estéticas únicas que não podem ser reproduzidas sem perdas. Ademais, um filme e, por conseguinte, seu processo de restauração, estão intrinsecamente ligados à tecnologia e ao seu desenvolvimento. Ou seja, o restauro sempre carrega as características do período em que foi realizado.

Também no discurso em torno do original, a tensão entre os artefatos materiais e os artefatos conceituais ${ }^{12}$ torna-se central. $O$ original pode realmente ser um dos possíveis artefatos materiais (por exemplo, o negativo de câmera original ou o único fragmento existente recuperado pelo arquivo) ou um dos possíveis artefatos conceituais (por exemplo, o corte do diretor/produtor ou do filme, conforme exibido para o público) (FOSSATI, 20I0). Isto é, o original pode ser desde o filme como o cineasta queria, o filme como efetivamente foi realizado, ou o filme como ele foi recuperado pelo arquivo em um dado momento, carregando as marcas da deterioração do material.

O conceito de original tem uma grande implicação na prática da restauração, pois orienta as intenções pretendidas pelos profissionais de restauro em um processo de trabalho. Desta forma, é fundamental discutir e questionar a ideia tradicional de original para a definição do conceito de restauração, e procurar uma acepção mais adequada ao contexto das artes que se caracterizam por sua reprodutibilidade, como a audiovisual. Questões essenciais como as que envolvem a autenticidade e proveniência das imagens em movimento e dos sons registrados fisicamente, por exemplo, além dos aspectos metodológicos e éticos, nunca foram debatidas na mesma proporção - tanto pela crítica de cinema quanto pelos acadêmicos - da maioria das outras atividades culturais baseadas em registros permanentes.

\section{O contexto histórico}

Apesar de o aprofundamento da discussão em torno dos conceitos de restauração audiovisual ter se dado a partir dos anos 2000, é importante ressaltar que suas práticas começaram a ser sistematizadas a partir dos anos 1980.

\footnotetext{
10 No original:"The 'original' version of a film is a multiple object fragmented into a number of different entities equal to the number of surviving copies".

II Cherchi Usai procura entender os artefatos fílmicos que compõem as imagens em movimento utilizando a mesma referência da restauração nas artes plásticas, onde cada objeto é considerado como o original, conforme veremos mais adiante através das formulações teóricas de Cesare Brandi (2005).

12 Conceitos desenvolvidos por Giovanna Fossati (2010). Para a autora, os artefatos conceituais são entendidos como as diferentes versões de um filme.
} 
Três festivais surgidos nessa década foram importantes para chamar atenção sobre a iminente perda dos filmes e, ao mesmo tempo, para iniciar o processo de consolidação da área. São eles: Le Giornate del Cinema Muto (mais conhecido como Festival de Pordenone), criado em 1982; II Cinema Ritrovato, surgido em 1986 e organizado pela Cinemateca de Bolonha; e Cinémemoire, organizado pela Cinemateca Francesa e cuja primeira edição aconteceu somente em $1991^{13}$

As chamadas restaurações editoriais, práticas correntes nos arquivos de filmes antes da década de 1980, eram constituídas por procedimentos que visavam a recuperação da ordenação original de um filme que porventura tivesse sido adulterado por motivos diversos (cortes de censura ou de produtores, versões para televisão, motivação do diretor, entre outros), priorizando o aspecto narrativo das obras. Convencionou-se denominar restauração editorial o processo cujo objetivo principal é o restabelecimento da montagem original da obra, realizada tanto a partir de dados do roteiro do filme quanto por meio de fotografias. Uma vez que não intervém diretamente nos constituintes imagéticos e sonoros de um filme, a restauração editorial também costuma ser classificada por alguns autores como sendo recuperação ou reconstrução (BUARQUE, 20I I). Também pode ser compreendida como uma outra dimensão do original, visto que o procedimento inclui a intenção de retornar à uma determinada condição original, ao menos no que diz respeito à ordenação das imagens.

A compreensão da restauração audiovisual como processo de restituição da integridade visual e sonora de um filme começou a se disseminar, de fato, somente a partir dos anos 1980, sendo que os festivais anteriormente citados contribuíram de maneira decisiva para a propagação desse entendimento. As discussões ocorridas nos congressos da Federação Internacional de Arquivo de Filmes (FIAF) em 1986 e 1987 também foram cruciais nesse sentido.

Apesar disso, foi somente a partir dos anos 2000 que um conjunto de publicações mais aprofundadas sobre os aspectos concernentes à restauração audiovisual começou a ser lançado ${ }^{14}$.

O progressivo aumento da quantidade de filmes restaurados a partir dos anos 1980, devido, possivelmente, à importante vitrine que os festivais mencionados acima criaram, e a introdução das tecnologias digitais na restauração audiovisual provocaram transformações substanciais e ofereceram possibilidades de intervenção tecnicamente inviáveis até cerca de uma década atrás, levantando questões de natureza ética que vêm fomentando intensos debates. É importante ressaltar que a FIAF, organização que reúne as mais importantes instituições de guarda de imagens em movimento, fundada em 1938, só lançou seu Código de Ética em $1998^{15}$. A publicação não estabelece normas ou recomendações vol-

13 O festival Cinémemoire não existe mais, mas não conseguimos localizar informações sobre seu período de existência e sua data de término até o momento. Desde 2012, a Cinemateca Francesa organiza o festival Toute la mémoire du monde, também dedicado ao universo da restauração audiovisual. Nos últimos anos, o tema tem estado presente em festivais como o de Cannes e o de Berlim, com os programas Cannes Classics e Berlinale Classics, dedicados à exibição de títulos, considerado clássicos, restaurados.

14 Entre esses trabalhos, além dos de Paolo Cherchi Usai (2000 e 2002), Paul Read e Mark-Paul Meyer (2000) e Julia Wallmüller (2007), já citados, podemos destacar a tese de Arianna Turci, Digital restoration within european film archives (2004), além de seu artigo The use of digital restoration within european film archives: a case study (2006), artigos de Andreas Busche, como Just another form of ideology? Ethical and methodological principles in film restoration (2006) e o livro de Giovanna Fossati, From grain to pixel (2010).

15 No preâmbulo do texto já encontramos novamente a ideia de original:"Arquivos de filmes e arquivistas de filmes são os guardiães do patrimônio mundial de imagens em movimento. É sua responsabilidade proteger esse patrimônio e transmiti-lo à posteridade nas melhores condições possíveis e na forma a mais fiel possível da obra original". $O$ único trecho que se refere diretamente à restauração é o seguinte: "Ao restaurar materiais, os arquivos se empenharão em completar o incompleto e em eliminar a ação do tempo, do uso e do mau uso. Não modificarão nem distorcerão a natureza dos materiais originais, ou a 
tadas especificamente para a restauração de filmes, mas sim uma conduta ética global para os arquivos de imagens em movimento.

Ainda que os parâmetros éticos sejam fundamentais para definir os limites dentro dos quais o trabalho de restauração audiovisual deva ser realizado, a conduta ética invocada, muitas vezes, como o eixo primordial na prática dos arquivos de filme, não pode ser encarada como universal, ou seja, como um procedimento único que dê conta de todo e qualquer processo de restauro. Dependendo do quadro teórico específico priorizado quando da realização de um projeto de restauração, um variado conjunto de posições éticas pode ser invocado.

Os conceitos de Cesare Brandi ${ }^{16}$ sobre restauração, desenvolvidos especialmente em Teoria da restauração, de 1963, serviram para construir a base teórico-metodológica do campo de restauração audiovisual e partem de outros pressupostos. Seus conceitos impactaram profundamente a área, tanto que as discussões ocorridas nos congressos da FIAF, em 1986 e 1987, tiveram como baliza a teoria desenvolvida por ele.

Embora localizadas no campo das artes plásticas, as formulações de Brandi reuniram, ao mesmo tempo, questões filosóficas, éticas e práticas da restauração, dando passos primordiais para a consolidação da área como campo disciplinar e buscando associá-la ao pensamento crítico e às ciências, em contraponto ao empirismo que prevalecera até então.

\begin{abstract}
Em meados do século 20, por proposições de variados autores, passa-se a encarar o restauro como ato histórico-crítico, o qual deve respeitar as várias fases por que passou a obra e preservar as marcas da própria translação da obra no tempo. Ademais, assume-se que qualquer ação sobre a obra intervém inexoravelmente em sua realidade figurativa, e a restauração assume para si a tarefa de prefigurar e controlar, justificar e fundamentar essas alterações, respeitando seus aspectos documentais, materiais e formais. (KÜHL, 2007: 199).
\end{abstract}

Para o autor, a "restauração é qualquer intervenção voltada a dar novamente eficiência a um produto da atividade humana” (BRANDI, 2005: 25). Mas ele defende que é no ato do reconhecimento da obra de arte como tal, que as premissas e condições da relação da restauração com a obra são reveladas. A partir desse reconhecimento, o restaurador encontrará a dúplice instância estética e histórica que deverá ser pesada e avaliada durante todo o processo de restauro. Essa dupla instância da obra de arte é um dos pontos centrais de sua teoria. $A$ instância estética considera as características da "artisticidade" 17 da obra. $A$ instância histórica traz a contextualização da obra quanto ao tempo e lugar em que foi realizada e o presente do processo de restauração. Brandi afirma:"A restauração constitui o momento metodológico do reconhecimento da obra de arte, na sua consistência física e na sua dúplice polaridade estética e histórica, com vistas à sua atuação prática" (BRANDI, 2005: 30).

Segundo o autor - e talvez seja esta a chave do conceito de restauração de Brandi - a restauração dos objetos de arte não deve satisfazer à mera função

intenção de seus criadores". Disponível em http://cinemateca.gov.br/sites/default/files/Codigo_Etica_FIAF. pdf .Acesso em: 05/03/20I8.

16 Cesare Brandi (1906-1988) é um dos principais nomes da restauração de obras de arte, tendo sido um dos responsáveis pela fundamentação do conceito de restauro crítico.

17 "Artisticidade" é um neologismo criado por Brandi. 
de recuperação da integralidade de um objeto, uma vez que está intervindo não em um objeto industrial stricto sensu, mas em um objeto reconhecidamente artístico, e cuja intervenção deve se balizar fundamentalmente por essa condição.

Embora os profissionais da área audiovisual tenham chegado bem mais tarde à esta discussão, a lacuna teórica sobre a restauração audiovisual vem, paulatinamente, sendo preenchida. No Brasil, o aumento do número de estudos sobre preservação audiovisual, conforme citado acima, e da quantidade de filmes restaurados no país a partir dos anos 2000 têm estimulado as pesquisas sobre a área de restauração ${ }^{18}$.

Em relação ao entendimento sobre o conceito de original no universo audiovisual, e, especialmente, em uma restauração, o ponto crucial diz respeito à necessidade de se determinar qual versão está sendo manipulada e ganhará o estatuto de matriz. As soluções serão diferentes para cada filme, de acordo com as evidências que possam ser encontradas e com a tecnologia e orçamentos disponíveis. A documentação de todo o processo é absolutamente necessária e deve acompanhar todo o percurso do trabalho, visto que cada decisão pode resultar em intervenções que se perpetuarão e acompanharão a trajetória de um filme deste momento em diante, até o seu (provável) desaparecimento. Diferente de Metropolis (Fritz Lang, 1927), que foi restaurado diversas vezes ${ }^{19}$, a maior parte das obras fílmicas que passam por procedimentos de restauro podem vir a não ter outra oportunidade, o que aumenta consideravelmente a responsabilidade das decisões e ações executadas durante o processo.

\section{A questão do conceito de original na prática da restauração: o caso Bonequinha de seda}

Com o intuito de explicitar as questões trazidas pela discussão acerca do conceito de original, teceremos algumas breves considerações a esse respeito a partir da restauração do filme Bonequinha de Seda (Oduvaldo Viana, 1936), realizada entre os anos de 2007 e $2013^{20}$.

Bonequinha de Seda foi produzido pela Cinédia ${ }^{21}$ e é considerado a primeira superprodução do cinema brasileiro, devido aos consideráveis avanços técnicos introduzidos na época: a utilização de novos equipamentos como a grua, efeitos como o back-projection ${ }^{22}$, além de cenários sofisticados construídos de forma contígua e utilização de maquetes. Foi o primeiro grande êxito artístico e financeiro da companhia e alcançou a maior bilheteria no mercado brasileiro até então ${ }^{23}$. Talvez, devido ao estrondoso sucesso, o filme não tenha tido o destino de tantas outras produções brasileiras da época, que desapareceram por conta

\footnotetext{
18 Ainda que a restauração audiovisual não tenha sido o foco principal das pesquisas acadêmicas sobre o campo da preservação até o momento, o tema vem sendo abordado, mesmo que tangencialmente, em grande parte dos trabalhos sobre a área.

19 Maiores informações sobre as diversas restaurações de Metropolis podem ser encontradas no texto The City of the future - $a$ realm of ruins, de Enno Patalas in: MINDEN, M. e BAHCMANN, H. (orgs.), 2000.

20 A coordenação técnica da restauração ficou a cargo da autora deste artigo e de Hernani Heffner, referência no campo da preservação audiovisual no Brasil, que atua como professor e conservador-chefe da Cinemateca do MAM-RJ.

2I A Cinédia foi fundada em 1930 pelo jornalista Adhemar Gonzaga, tendo sido responsável pela introdução dos estúdios de grande porte no país.

22 Back-projection é um sistema de projeção de uma imagem por trás de uma tela ou placa translúcida para resultar em um plano de fundo para o desenrolar de alguma ação à sua frente.

23 Estes dados sobre o filme Bonequinha de Seda encontram-se no verbete Cinédia, in: Enciclopédia do Cinema Brasileiro (MIRANDA, L.F. e RAMOS, F., orgs., 2000).
} 
de processamento laboratorial inadequado, destruição sistemática de cópias, guarda e acondicionamento fora de padrões mínimos de conservação e incêndios. Dado esse panorama, que não se restringe apenas às realizações deste período, a maior parte das restaurações de filmes brasileiros não têm como matrizes de seus trabalhos os negativos originais, mas materiais de difusão, como as cópias, que, em geral, se apresentam em estado de conservação precário.

Desta forma, como estabelecer o que seria o original? No caso de Bonequinha de Seda, pesquisar a trajetória dos materiais e de seus processos de reprodução foi essencial para se estabelecer quais seriam os parâmetros desse restauro, ou seja, de quais condições originais conseguiríamos nos aproximar e de que forma. Devido ao avançado estágio de deterioração do material remanescente, uma das prioridades da restauração foi produzir novas matrizes de preservação e difusão em película. Acrescida à essa ação emergencial, também foi necessário tentar recuperar a duração original de 120 minutos, pois, desde os anos 1970, o filme circulava nessa versão remontada e sem o trecho do número musical final. A avaliação histórica da obra feita até então deu-se, basicamente, pelo contato com esta versão reduzida.

Para entendermos, de maneira geral, os problemas e as soluções encontradas, precisamos voltar a 1948 e ao que aconteceu com os diferentes materiais a partir daí. Nesta época, ao se considerar o relançamento comercial de Bonequinha, descobriu-se que o filme já se encontrava bastante degradado. A pedido de Adhemar Gonzaga, produtor do filme, Alberto Botelho, conhecido cinegrafista e laboratorista do período, reuniu trechos dos negativos de imagem e de som e as cópias de exibição existentes, comparando-os, a fim de reconstituir a obra editorialmente para sua posterior duplicação e produção de novas cópias, que circularam apenas em 1952, data de sua reestreia. Com exceção do material reconstituído, uma cópia $35 \mathrm{~mm}$ em nitrato, os novos elementos produzidos a partir dele se perderam ou foram dados como perdidos, sem que se saiba, com exatidão, o que aconteceu com eles ${ }^{24}$. Deste modo, a versão reconstituída por Botelho serviu de base para a confecção de todos os outros elementos posteriores, tornando-se, de certa forma, a matriz original deste título. Esta reconstituição carregou todos os problemas dos materiais que lhe deram origem, tais como perda de fotogramas, riscos no suporte e emulsão abundantes e de variadas larguras e profundidades, além de arranhões em profusão nos finais e inícios de rolos. Grande parte destes danos foram causados pelo extraordinário sucesso do lançamento original: as frequentes exibições deixaram marcas diretas nas cópias da época.

A cópia reconstituída em 1952 foi duplicada novamente nos anos 1970, e essa duplicação, confeccionada sob a forma de um contratipo combinado ${ }^{25}$ em $35 \mathrm{~mm}$, além de algumas cópias sonoras em $16 \mathrm{~mm}$ confeccionadas pela Cinemateca Brasileira no laboratório cinematográfico Rex, em São Paulo. A Cinédia também confeccionou alguns outros materiais no laboratório Líder, no Rio de Janeiro, como um interpositivo ${ }^{26}$ e um contratipo, ambos com som, e cópias em $35 \mathrm{~mm}$. Algumas dessas cópias foram remontadas e reduzidas, tendo sido retirado a maior parte do número musical final. Desde então, o filme vinha cir-

24 Muito provavelmente foram destruídos no incêndio que acometeu a Cinemateca Brasileira em 1957. 25 Contratipo combinado é a denominação técnica de um material negativo, oriundo de duplicação, que conjuga imagem e som em um mesmo suporte fotoquímico.

26 Interpositivo é um termo técnico utilizado para qualquer reprodução positiva confeccionada a partir de emulsões especialmente elaboradas para servir como material intermediário para a obtenção de duplicações negativas. 
culando nessa versão alterada, até a grande enchente que ocorreu na cidade do Rio de Janeiro em fevereiro de 1996, sendo que um dos bairros mais afetados foi justamente Jacarepaguá, onde estava localizado o arquivo fílmico da Cinédia. O acervo audiovisual foi severamente prejudicado e desde então uma das prioridades da companhia foi a recuperação de sua filmografia e a restauração dos materiais, por meio de projetos sob a coordenação de Alice Gonzaga, filha de Adhemar Gonzaga.

Bonequinha de Seda foi um dos últimos títulos a ser restaurado e o único a passar por intervenções fotoquímicas e também digitais, através de um processo iniciado em 2007 e finalizado seis anos depois ${ }^{27}$. Por conta da importância do filme para a Cinédia - foi o primeiro grande sucesso da produtora - e devido ao avançado estágio de deterioração, sendo que tanto a imagem quanto o som encontravam-se bastante comprometidos, a incorporação das ferramentas digitais durante o processo se mostrou como uma possibilidade única na tentativa de restituir as qualidades estéticas da obra. A etapa fotoquímica, apesar de garantir a salvaguarda do título, ação urgente e primordial, não foi suficiente para a recuperação de um estado que pudesse ser considerado próximo ao original, pois grande parte da apreciação do filme ainda se encontrava comprometida pela deterioração e pelas sucessivas duplicações em condições bastante inadequadas.

A etapa digital consistiu no escaneamento do material em $2 \mathrm{~K}$ de resolução e sua restauração digital através do software Diamant desenvolvido pela empresa HS-Art, através de uma parceria realizada com o laboratório Labocine ${ }^{28}$, que estava implantando o setor à época e resolveu acolher o projeto como um caso modelo.

Conforme colocado acima, o objetivo inicial da restauração do filme era a confecção de novas matrizes de preservação e difusão em película fotoquímica. Após a etapa de pesquisa e comparação dos materiais remanescentes, o contratipo combinado confeccionado no laboratório Rex na década de 1970 foi escolhido como a matriz desse processo. Apesar do elevado grau de encolhimento e deformação do suporte e da fragilidade da emulsão, a qualidade fotográfica do material se mostrava superior em relação aos outros elementos. $O$ processamento fotoquímico teve que ser extremamente cuidadoso e sem maiores intervenções, visto o estado precário do material. Foram confeccionados um interpositivo combinado e uma cópia sonora, ambos em $35 \mathrm{~mm}$. Esta quarta geração de materiais transportou todos os problemas anteriores, pois já se encontravam impressos fotograficamente, e acrescentou alguns outros, como a visível deformação de certos trechos do filme e uma maior instabilidade e deslocamento lateral do quadro.

A partir dos resultados obtidos, a utilização das ferramentas digitais passou a ser efetivamente considerada, apesar da incerteza em relação ao seu alcance em uma obra como Bonequinha, cujas características dos materiais remanescentes já pareciam limitar de antemão as possibilidades de intervenção existentes. Ainda assim, os testes revelaram resultados promissores. Mas o estado de conservação dos materiais transformou o processo de restauração digital em um grande e longo desafio, que durou quase quatro anos.

27 Estas informações foram reunidas durante a pesquisa para o processo de restauração a partir de documentos do acervo da Cinédia e de depoimentos, como o de Alice Gonzaga, filha de Adhemar Gonzaga e atual responsável pela preservação do patrimônio da companhia.

28 Em 1998, a Líder é comprada pelo investidor e empresário Wilson Borges e passa a se chamar Labocine. 
Os problemas surgiram logo durante o processo de escaneamento. $O$ scanner da Labocine, o Northlight da empresa inglesa Filmlight, não ofereceu capacidade de processamento adequada para o grau de encolhimento apresentado pelo filme, o que ocasionou a interrupção durante o processo de captura das imagens e provocou tensionamento excessivo do material, o que poderia enfatizar o desprendimento da emulsão, já bastante fragilizada. Foram então realizados novos testes com alguns rolos das cópias incompletas que sobreviveram à enchente e também com o interpositivo, que já trazia incorporado fotograficamente os danos físicos e químicos do material que lhe deu origem, ou seja, o contratipo realizado na Rex. A tentativa de equilibrar fotograficamente elementos de diferentes origens não se mostrou satisfatória, e o interpositivo acabou sendo escolhido como a matriz para o escaneamento.

As primeiras etapas de tratamento do material no software Diamant, tanto na modalidade automática quanto semiautomática, se mostraram bastante satisfatórias em relação a determinados ruídos visuais presentes (principalmente os criados por Botelho durante o processo de reconstrução física do material em 1952, como resquícios de cola nas emendas, inscrições de números e símbolos realizados diretamente na película) e às distorções de quadro, sobretudo as laterais. Já no que se refere aos riscos e arranhões, entretanto, a resposta foi mínima, revelando uma limitação inerente à esta forma de dano. Tentou-se interferir de maneira mais drástica e o resultado foi ainda pior, com a criação de inúmeros artefatos e a acentuação de algumas deformações na tentativa de estabilização geral ou parcial dos quadros. Ou seja, no geral, a atuação da ferramenta digital não trouxe resultados significativos para os problemas considerados mais graves e de maior intensidade.

Após a exibição de algumas amostras do trabalho e consultas a especialistas em eventos internacionais ${ }^{29}$, comprovou-se que os procedimentos adotados estavam, a princípio, corretos, e que, infelizmente, a atuação dos softwares de restauração nos danos apresentados pelo filme não teria a repercussão desejada, ao menos não na versão em que se encontravam. Durante esse período, o software recebeu importantes atualizações e novos testes foram realizados no modo de limpeza manual, fotograma por fotograma. Os resultados foram considerados bem mais satisfatórios, e os ganhos em relação à restauração fotoquímica se mostraram evidentes. Dado a especificidade dos problemas apresentados pelo filme, se estabeleceu um canal de comunicação permanente entre - laboratório e a HS-Art, o que viabilizou aperfeiçoamentos específicos para a limpeza dos riscos e arranhões incorporados fotograficamente, ocorrendo até mesmo a vinda de um dos representantes do setor de desenvolvimento e manutenção da empresa ao Brasil.

Nem todos os problemas foram completamente solucionados, as ferramentas de estabilização da imagem e eliminação de distorções causadas pelo abaulamento $^{30}$, por exemplo, não se demonstraram suficientes. Ademais, uma limpeza realmente profunda excederia o tempo e recursos disponíveis, sendo que o processo de restauração digital já totalizava cerca de quatro anos. Mas

29 Leonardo Puppin, responsável técnico pelo trabalho na Labocine, esteve no National Association Broadcasters Show, nos EUA, em 2008 e a co-restauradora do filme e autora deste artigo apresentou as amostras durante o Taller de Altos Estudios sobre Preservación Fílmica, na Escola Internacional de Cinema e TV de Santo Antonio de Los Baños, em Cuba, também em 2008, e no FIAF Summer Restoration School, realizado no laboratório de restauração audiovisual L'Immagine Ritrovata, na Itália, em 2010.

30 Abaulamento é um termo utilizado para os diferentes tipos de deformação causadas pelo encolhimento irregular do suporte, bem comum nos materiais de acetato de celulose, como é o caso de Bonequinha de seda. 
dado o estado de deterioração em que Bonequinha de Seda se encontrava, o resultado alcançado pode ser considerado notável.

A condição original, no caso de Bonequinha de Seda, já manifestava determinadas características bem peculiares que poderiam ser confundidas com defeitos e serem passíveis de intervenção. Em relação ao que teria sido a condição fotográfica original do filme, por exemplo, a flutuação de luz presente nas imagens provavelmente foi causada pelo processamento laboratorial do período, realizado de forma manual através do método de cuba e tear. Não seria um defeito passível de correção, portanto, mas sim um dado histórico inerente ao processo de finalização da época. No caso do som, cuja restauração - bem mais simples e bem-sucedida - foi realizada pelo estúdio de som Rob Filmes a partir da transcrição de todos os materiais sonoros remanescentes, a retirada do excesso de ruído ocasionado pelos riscos e arranhões revelou uma banda sonora bem menos harmoniosa do que parecia a princípio. Até então encobertos, os cortes secos e as passagens sem fusão entre música e diálogos, acrescidos das limitações acústicas dos estúdios de filmagem, vieram à tona através do processo de restauro. Características que, mais uma vez, poderiam ser encaradas como defeitos, mas, entretanto, revelaram propriedades específicas da produção cinematográfica brasileira do período e foram, portanto, ser mantidas.

Dos 120 minutos de duração originais, atualmente encontram-se perdidos cerca de 5 minutos, sendo que nenhuma cena ou sequência está desaparecida por completo. $O$ filme tornou-se menos irregular, truncado, ilegível, por conta da retirada de um sem número de camadas de elementos estranhos (correspondentes às deteriorações incorporadas fotograficamente através da reprodução de todos os problemas de manipulação e deterioração das gerações anteriores elencados acima) ao registro audiovisual de 1936. Está mais próximo de sua condição original, muito embora seja difícil precisar, neste caso específico, qual seria, de fato, tal condição.

\section{Considerações finais}

A experiência de fruição de uma obra cinematográfica na forma consagrada durante o século $X X$, isto é, o padrão fotoquímico, acarreta, inevitavelmente, a deterioração de sua materialidade. Sejam os materiais de difusão, as cópias de exibição propriamente ditas, ou os elementos que as deram origem, como os negativos de imagem e som. Por este motivo, o que se apresenta para os profissionais de restauração audiovisual como base de trabalho são materiais com diversos níveis e extensão de danos, tanto físicos como químicos, e/ou, ainda, em diferentes versões. Determinar, diante desta variedade de elementos e em estados de conservação díspares, o que seria o estado original desta obra é uma tarefa árdua, que, de certa forma, está fadada à impossibilidade. Ou seja, o conceito de original parece servir muito mais como um postulado teórico do que uma ação exequível de fato. Por conseguinte, a admissão de que esse estado original é uma condição que se alcançará, sempre, de maneira aproximada, deveria ser premissa básica de um processo de restauração audiovisual.Ainda assim, essa aproximação deve estar baseada em critérios rigorosos de pesquisa acerca da genealogia dos materiais, que inclui desde os métodos de processamento laboratorial, as características intrínsecas da natureza de cada tipo de emulsão e suporte, o histórico de manuseio até a trajetória de acondicionamento, conservação e degradação, além dos documentos correlatos que podem auxiliar nesta operação. 
No Brasil, dada a pouca atenção dispensada à conservação do patrimônio audiovisual do país, dificilmente os projetos de restauração contam com diversos materiais como base de trabalho, especialmente no que se refere aos negativos originais, que, em grande parte, não sobreviveram. $O$ caso de Bonequinha de Seda é exemplar neste sentido, acrescidas as características técnicas da produção cinematográfica brasileira do período. Desta forma, um processo de restauro fílmico no Brasil tem, desde o princípio, seu escopo limitado. Além disso, com o encerramento das atividades dedicadas ao processamento de materiais fotoquímicos nos laboratórios cinematográficos brasileiros ${ }^{31}$ nos últimos anos, as limitações serão ainda mais severas.

\section{Referências}

BRANDI, Cesare. Teoria da Restauração. São Paulo:Ateliê Editorial, 2005. BUARQUE, Marco Dreer. Entre grãos e pixels, os dilemas éticos na restauração de filmes: o caso de Terra em transe. Dissertação (Mestrado), Centro de Pesquisa e Documentação de História Contemporânea do Brasil, Rio de Janeiro, $201 \mathrm{I}$. BUSCHE, Andreas. Just Another Form of Ideology? Ethical and Methodological Principles in Film Restoration. The Moving Image, volume 6, number 2, fall 2006, PP. I-29. University of Minnesota Press.

CHERCHI USAI, Paolo. Film as an art object. In: NISSEN, Dan et al (orgs.). Preserve Then Show. [s.l.]. Danish Film Institute, 2002, pp. 28-38. . Silent Cinema: an introduction. London: British Film Ins-

titute, 2000.

COELHO, Maria Fernando Curado. A experiência brasileira na conservação de acervos audiovisuais: um estudo de caso. Dissertação (Mestrado em Ciências da Comunicação), Escola de Comunicação e Artes da Universidade de São Paulo (USP), São Paulo, 2009.

COSTA, Joice Scavone. "Mulher": a trajetória do som no primeiro longa-metragem 'synchronizado' da Cinédia. Dissertação (Mestrado em Comunicação), Instituto de Arte e Comunicação Social da Universidade Federal Fluminense (UFF), Niterói, 2013.

COSTA, Silvia Ramos Gomes da. Ondas de destruição: a efemeridade do artefato tecnológico e o desafio da preservação audiovisual. Dissertação (Mestrado em Memória Social), Universidade Federal do Estado do Rio de Janeiro (UNI-RIO), Rio de Janeiro, 2013.

EDMONDSON, Ray. Filosofia e princípios da arquivística audiovisual. Rio de Janeiro: ABPA; Cinemateca do MAM-RJ, 2013.

FOSSATI, Giovanna. From Grain to Pixel: The Archival Life of Film in Transition. Amsterdam:Amsterdam University Press, 2010.

HEFFNER, Hernani e RAMOS, Lécio Augusto. Verbete Cinédia. In: RAMOS, F. e MIRANDA, L. F. (orgs.). Enciclopédia do cinema brasileiro. São Paulo, Ed. SENAC, 2000, pp. I30-I 32.

KÜHL, Beatriz Mugayar. Cesare Brandi e a teoria da restauração. Pós. Revista do Programa de Pós-Graduação em Arquitetura e Urbanismo da FAU-USP, [s.I.], n. 2I, p. 197-2II, jun. 2007. ISSN 23 I7-2762. Disponível em: <http://www.revistas. usp.br/posfau/article/view/435 I6>. Acesso em: 20 jan. 2017.

PATALAS, Enno. The City of the future - a realm of ruins. On the work of the Munich Film Museum. In: MINDEN, Michael e BAHCMANN, Holger (orgs.). Fritz

$31 \quad$ Mesmo com o funcionamento precário, por conta do número reduzido de funcionários, a única exceção é o Laboratório de Restauração da Cinemateca Brasileira, em São Paulo. 
Lang's Metropolis: Cinematic visions of technology and fear. Rochester, NY: Camden House, 2000, pP. III I 22.

READ, Paul; MEYER, Mark-Paul. Restoration of Motion Picture Film. Oxford: Butterworth-Heinemann, 2000.

SOUZA, Carlos Roberto de. A Cinemateca Brasileira e a preservação de filmes no Brasil. Tese de Doutorado, Escola de Comunicação e Artes da Universidade de São Paulo (USP), São Paulo, 2009.

TURCI,Arianna. Digital Restoration Within European Film Archives (tese). University of Amsterdam, 2004.

. The Use of Digital Restoration Within European Film Archives:A Case Study. The Moving Image, Volume 6, Number I, Spring 2006, Pp. I I I124. University of Minnesota Press.

VASQUES,Alexandre Ramos. Nos rastros de Limite: um estudo de caso na história da preservação das imagens em movimento no Brasil. Dissertação (Mestrado), Programa de Pós-Graduação em Imagem e Som, Universidade Federal de São Carlos, 2012.

WALLMÜLLER, Julia. Criteria for The Use of Digital Technology in Moving Image Restoration. The Moving Image, Volume 7, Number I, Spring 2007, pp. 78-9I. University of Minnesota Press. 